\title{
The Antecedents and Consequences of Small Enterprise Organizational Ambidexterity: An Empirical Analysis of Italian Manufacturing Firms
}

\author{
Francesco Ciampi ${ }^{1}$ \\ ${ }^{1}$ Department of Economics and Business, Florence University, Florence, Italy \\ Correspondence: Francesco Ciampi, Department of Economics and Business, Florence University, Florence, \\ Italy. E-mail: francesco.ciampi@unifi.it
}

Received: November 28, 2017

Accepted: December 16, 2017

Online Published: December 20, 2017

doi:10.5539/ijbm.v13n1p110

URL: https://doi.org/10.5539/ijbm.v13n1p110

\begin{abstract}
This study contributes to the emerging dialogue on the relationships between top management team (TMT) functional background diversity, organizational ambidexterity and company performance. Although small firms (SEs) represent a fundamental component of every nation's economy, to our knowledge SEs have never been considered as specific units of analysis in the context of this dialogue. Therefore, logistic regression was applied to a sample of 502 Italian manufacturing SEs, 244 operating in the fashion industry and 258 operating in other low technology industries. The principal findings are the following: i) there is a significant and positive relationship between SE TMT diversity and SE organizational ambidexterity; ii) the chief executive officer's (CEO's) functional background and power act as moderators in this relationship; iii) there is a significant and positive relationship between SE organizational ambidexterity and SE performance and this relationship is positively moderated by the level of complexity of the industry environment.
\end{abstract}

Keywords: CEO functional background, CEO power, organizational ambidexterity, top management team diversity

\section{Introduction}

Small firms (SEs) represent a fundamental component of every nation's economy. Considering the definition of SEs used in this study (firms with a turnover of less than 5 million euros), in Italy about $62 \%$ of all firms are SEs and they employ about $47 \%$ of the workforce.

SEs also have their own specific characteristics, which are markedly different from those of larger firms. For example, SEs have a "personal" character, with the majority shareholder and the chief executive officer (CEO) who are often one and the same person (Burke \& Jarrat 2004; Ciampi, 2015; Ciampi \& Gordini 2013). From this it follows that SEs normally act quicker and are more reactive when facing environmental challenges.

Nevertheless, to our knowledge, the emerging dialogue on the relationships between top management characteristics, the CEO's role, organizational ambidexterity and performance has mainly focused on large firms, only exceptionally on small and medium sized firms (e.g., Lubatkin, Simsek, Ling, \& Veiga, 2006), on young entrepreneurial firms (Parida, Lahti, \& Wincent, 2016), and on new ventures (Song \& Jin, 2017), but never specifically on SEs.

This paper contributes to filling this gap by applying logistic regression to a sample of 502 Italian independent low-technology manufacturing SEs, and by providing a SE-level discussion on the antecedents and consequences of organizational ambidexterity.

More specifically, this study analyses the relationships between SE top management functional background diversity, organizational ambidexterity and company performance, and investigates the moderating role played by CEO characteristics and by the level of complexity of the industry environment.

One of the findings is that SE Top Management Team (TMT) diversity is particularly beneficial for simultaneously pursuing exploratory and exploitative innovation, and that a SE's CEO generality (power) positively (negatively) moderates the relationship between TMT diversity and organizational ambidexterity. Another finding is that also in the case of SEs, Organizational Ambidexterity is a key driver for value creation, 
and that the complexity of the industry environment acts as a moderator of the relationships between organizational ambidexterity and SE performance.

The next part of the paper proposes the research hypotheses contextualized in the literature on the relationships between TMT characteristics, the CEO's role, ambidexterity and performance. Following this, the proposed variables will be presented and the sample analysed will be described. Finally, the research results will be presented and discussed, and the conclusions formulated.

\section{The Research Hypotheses in the Context of the Existing Literature}

\subsection{The Emerging Dialogue on the Relationships between TMT Characteristics, the CEO's Role, Ambidexterity, and Performance}

Over the past fifteen years many studies of organization, strategic management and innovation literature have emphasized that success and long-term survival of firms highly depend on their capacity to operate ambidextrously, which is the ability to concurrently pursue, synchronize and balance exploratory and exploitative innovation (Lubatkin et al., 2006). Exploitation focuses on refining and extending current knowledge, thus leading to incremental innovation (Atuahene-Gima, 1996). In contrast, exploration builds on the development of new knowledge, thus leading to a more radical innovation (Andriopoulos \& Lewis, 2009).

According to the upper echelon perspective (Hambrick \& Mason, 1984), the demographic features of top management members can be considered as being reliable proxies of their cognitive base, vision and values. It can be consequently assumed that these features have an influence on a firm's ambidexterity.

However, the strength of these relationships depends on the quality of the behavioural integration processes of TMTs and on the propensity of the members of the team to effectively implement exchange processes relating to the information at hand (Dahlin, Weingart, \& Hinds, 2005). The effectiveness of these activities depends, in turn, on the ability of CEOs to guide these exchange and integration processes (Hambrick, 1995).

This emerging literature on the relationships between TMT characteristics, the CEO's characteristics, organizational ambidexterity and company performance, has mainly focused on large firms, only exceptionally on small and medium sized firms (e.g., Lubatkin et al., 2006), and never specifically on SEs.

\subsection{Research Hypotheses}

Hambrick and Mason's (1984) "upper echelon perspective" stimulated several studies on the relation between the demographic composition of the top management team (TMT), organizational behaviours and company performance (Certo, Lester, Dalton, \& Dalton, 2006). The information-processing perspective (Hambrick, Cho, \& Chen, 1996) states that the TMT composition influences TMT cognitive models and, as a consequence, impacts on strategic decision making. In particular, some studies found that TMT diversity is particularly beneficial for strategic thinking, especially when it requires substantial judgment and creativity (Millikens \& Martin, 1996). Based on these perspectives, this paper argues that the more diverse functional backgrounds SE top management members have, the more they can use different information, different decision-making styles and different professional perspectives. As a consequence, also in SEs TMT diversity seems to facilitate simultaneously pursuing exploratory and exploitative innovation. Consequently:

H1: In SEs TMT diversity is positively related to organizational ambidexterity.

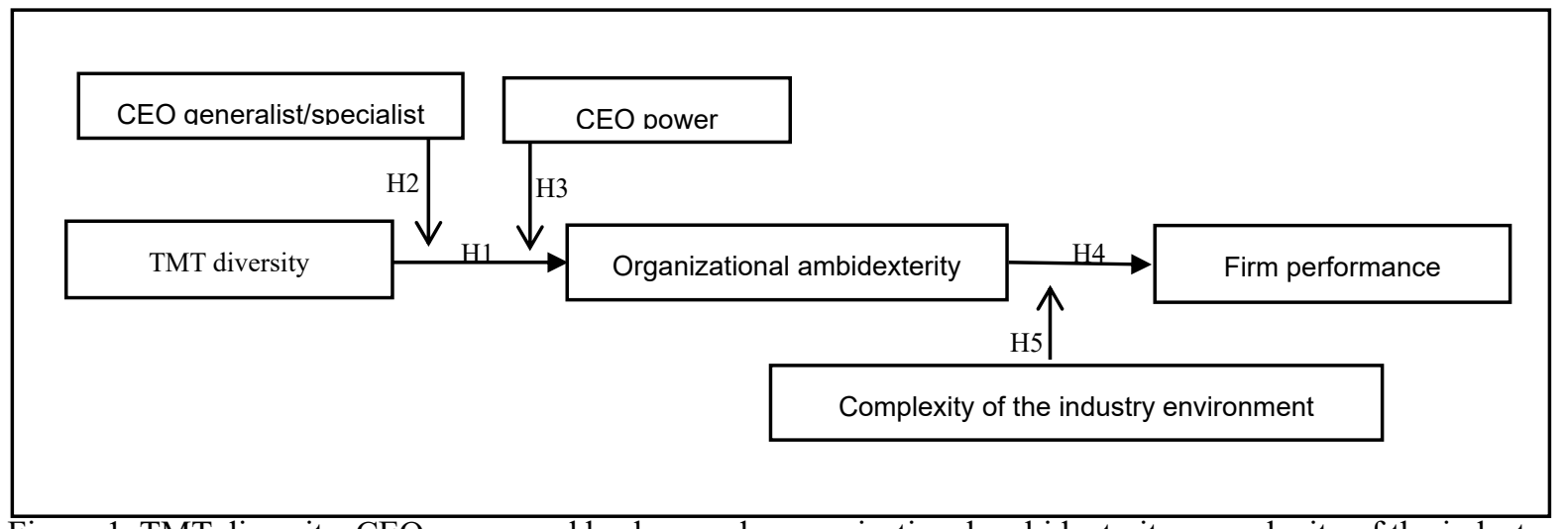

Figure 1. TMT diversity, CEO power and backgrounds, organizational ambidexterity, complexity of the industry context and SE performance 
On the other hand, TMT diversity might also generate separation and fragmentation, which are major sources of the ineffective functioning of teams (Hambrick \& Mason, 1984). Hambrick (1994) argued that the relationship between TMT functional diversity and organizational outcomes is intermediated by the behavioural integration of teams. Diverse teams effectively use their asymmetric functional information only if members effectively exchange and integrate the information at hand (Ling \& Kellermanns, 2010), and the behaviour of CEOs is of the utmost importance in guiding these exchange and integration processes (Hambrick, 1995). Building on the CEO-TMT interface research stream (e.g. Jansen, George, Van den Bosch, \& Volberda, 2008), which assumes that TMT performance jointly depends on team and leader dynamics and interactions, we expect that generalist SE CEOs (i.e. SE CEOs with a broad functional background experience) are better able to develop shared understandings and beliefs (Chattopadhyay, Glick, Miller, \& Huber, 1999) and they will also be less susceptible to functionally grounded stereotypes (Bunderson \& Sutcliffe, 2002). Furthermore, we expect that powerful SE CEOs will be less susceptible to dialogue with other TMT members (Adams, Almeida, \& Ferreira, 2005), will be likely to weaken their psychological safety, and will discourage the expression of deviant opinions (Carmeli \& Schaubroeck, 2006). These considerations suggest our second and third hypothesis.

H2: In SEs the functional background of the CEO moderates the relationship between TMT diversity and organizational ambidexterity; specifically, the relationship between TMT diversity and ambidexterity is strengthened/weakened when the CEO is a generalist/specialist.

H3: In SEs the CEO power moderates the relationship between TMT diversity and organizational ambidexterity; specifically, the less powerful the CEO, the greater the positive relationship between TMT diversity and ambidexterity.

Even if this link has not been clearly demonstrated so far (Ghemawat \& Costa, 1993), the positive association between ambidexterity and performance has often been underlined in the literature (e.g., Gibson \& Birkinshaw 2004). Thus, the fourth hypothesis is based on the assumption that the capability of small firms to be adaptive and to successfully face the forces of environmental selection depends on their ability to contemporarily exploit existing competencies and explore new competencies (Floyd \& Lane, 2000). Consequently:

H4: In SEs organizational ambidexterity is positively related to firm performance.

Different industry environments are characterized by different levels of competitive complexity and, as a consequence, by different levels of managerial discretion (Hambrick, Finkelstein, \& Mooney, 2005; Finkelstein \& Hambrick, 1990). Consequently, the more the industry context is complex, the greater the need for organizational flexibility and ambidexterity. We can therefore expect that the level of complexity of the industry environment impacts positively on the relationship between SE organizational ambidexterity and performance. These arguments suggest our last hypotheses.

H5: In SEs the level of complexity throughout the industry environment moderates the relationship between organizational ambidexterity and company performance; specifically, the more complex the industry context, the greater the positive relationship between ambidexterity and performance.

\section{Research Methods}

\subsection{Variables}

This study uses the following variables: TMT functional background diversity, CEO generalist/specialist, CEO power, organizational ambidexterity, company performance, and complexity of the industry environment.

TMT functional diversity was measured by asking the CEO to indicate all the TMT members and identify the dominant functional expertise for each of them by choosing from the following six areas: finance, accounting, marketing, operations, R\&D, and human resource. Subsequently, TMT functional background diversity was quantified using Blau's heterogeneity index (Blau, 1977).

For the generalist-specialist variable, the general skills index proposed by Custodio, Ferreira, and Matos (2013) was used, which measures the generality of a CEO considering the number of positions, firms, and industries in which he/she worked, whether he/she occupied the same executive position in different companies and whether he/she worked for a conglomerate.

The CEO's power was measured by the sum of the following items: CEO duality (Daily \& Johnson, 1997), valued 1 if the $\mathrm{CEO}$ is also the chairman of the board, and 0 otherwise; CEO shareholder status, measured as the percentage of the company stock owned by the CEO, excluding options (Zhou, 2001), and CEO information power, valued 1 if the CEO is the only insider (executive/employee) on the board and 0 otherwise (Adams et al., 2005). 
Organizational ambidexterity was measured following Lubatkin et al. (2006), as the sum of 6 items referred to explorative orientation and 6 items referred to exploitative orientation.

Compared to other low-technology manufacturing contexts, the fashion industry is characterized by higher levels of competition, product differentiability, and demand instability. It can be therefore expected that fashion firms face higher levels of environmental complexity compared to firms operating in other low-technology manufacturing industries. Consequently, complexity of the industry environment was valued 1 if the firm operated in the fashion industry and 0 otherwise.

Company performance was measured as return on total assets: net income from continuing operations, excluding extraordinary items, divided by total assets.

This study checked for firm size (measured by the natural logarithm of the firm's turnover), firm location (three dummy variables concerning the geographical location: NW, NE, Centre or South Italy; "Centre" was used here as the reference category), firm age (the number of years since the company was established), firm family ownership (a dummy variable with a value of 1 if the majority of shares with voting rights was owned by members of the same family, 0 otherwise), TMT tenure (measured by the average tenure of all TMT members transformed by its square), and TMT size (measured by the total number of individuals on a company's TMT transformed by its square).

\subsection{Sample, Data Collection and Statistical Method}

The initial sample consisted of 2,066 independent Italian SEs operating in low-technology manufacturing industries. This sample was extracted from the CERVED Database (Note 1) and was selected by way of a two-step process. The first step was to select a sample of 1,033 firms primarily operating in one of the business sectors of the fashion industry (textile, clothing, jewellery, footwear, leather and tanning), which in 2015 were independent (i.e. not part of a group), had a regular balance sheet, and a turnover below 5 million Euros. This sample was selected by stratified random sampling, with the aim of obtaining a sample as representative as possible of the correspondent population with regard to size (measured by 2015 turnover) and business sector. The second step was to select a sample of the same size (1,033 firms) comprising firms primarily operating in the other (i.e. non-fashion) low-technology manufacturing industries, which in 2015 were independent (i.e. not part of a group), had a regular balance sheet and a turnover below 5 million Euros. This second sample was also selected by stratified random sampling based on size and business sector.

The company performance variable was calculated on balance sheet data related to the 2015 financial year and extracted from the CERVED Database. The variables regarding firm size, location, age and industry were also extracted from the CERVED Database. The dataset of all the other variables was built by sending a questionnaire to the CEO of each of the 2,066 small firms included in the initial sample. $24.3 \%$ of firms sent back complete responses (244 fashion companies and 258 non-fashion companies).

Logistic regression analysis was used: 1) to explore the link between TMT diversity and organizational ambidexterity, and test the moderating effects of CEO power and CEO background; 2) to capture the effect of organizational ambidexterity on performance, and test the moderating effects of the complexity of the industry environment.

\section{Research Findings}

\subsection{Results}

The hypotheses were tested by first analysing the main effects and then entering each interaction effect separately. Variance inflation factors (VIF) were calculated from each regression function: results ranged from 1.18 to 6.91 , which is below the typical cut-off of 10 (Cohen, Cohen, West, \& Aiken, 2003).

Table 1 shows the results of regressing organizational ambidexterity on TMT diversity, CEO generality, and CEO power, as well as on the control variables (firm size, location, age, family ownership, TMT tenure and size).

In accordance with Hypothesis 1, SE TMT diversity was found to be significantly and positively correlated with SE ambidexterity (Model 1). Compared to larger firms, SE organizational structures are simpler and characterized by a far lower number of hierarchical levels. As a consequence, in comparison to their counterparts in larger firms, members of SE TMTs participate more directly in the day-to-day implementation of corporate strategies. They are closer to the firm's existing competencies and, therefore, better positioned to evaluate when and how to exploit them. At the same time, they are also closer to the markets and, therefore, better positioned to detect and explore new market opportunities (Lubatkin et al., 2006). The highly significant and positive relation found between SE TMT diversity and SE ambidexterity is fully coherent with these considerations. 
Model 2 and 3 show that:

a) the interaction between TMT diversity and CEO generality was found to be positively and significantly correlated with SE ambidexterity, thus confirming Hypothesis 2;

b) the interaction between TMT diversity and CEO power was found to be negatively and significantly correlated with SE ambidexterity, thus confirming Hypothesis 3.

Table 1. Results of regressing organizational ambidexterity on TMT diversity, CEO generality and CEO power

\begin{tabular}{|c|c|c|c|}
\hline \multicolumn{4}{|c|}{ DEPENDENT VARIABLE: ORGANIZATIONAL AMBIDEXTERITY } \\
\hline & MODEL 1 & MODEL 2 & MODEL 3 \\
\hline & \multicolumn{3}{|c|}{ LOGISTIC REGRESSION COEFFICIENTS } \\
\hline INTERCEPT & $-0.687 * *$ & $-0.754^{*}$ & $-0.697 *$ \\
\hline \multicolumn{4}{|l|}{ INDEPENDENT VARIABLES } \\
\hline TMT diversity & $+1.231 * *$ & $+0.987 * *$ & $+0.458 *$ \\
\hline CEO generality & +0.067 & +0.045 & +0.037 \\
\hline CEO power & -0.065 & -0.049 & -0.047 \\
\hline \multicolumn{4}{|l|}{ CONTROL VARIABLES } \\
\hline Firm size & -0.121 & -0.098 & -0.087 \\
\hline Firm age & -0.089 & -0.078 & -0.011 \\
\hline Firm family ownership & $-0.032 * *$ & $-0.021 *$ & $-0.014 *$ \\
\hline TMT tenure & +0.045 & +0.056 & -0.009 \\
\hline TMT size & +0.033 & +0.036 & +0.021 \\
\hline NW Italy & +0.565 & +0.321 & +0.565 \\
\hline NE Italy & -0.089 & -0.076 & -0.054 \\
\hline South Italy & +0.045 & +0.033 & +0.041 \\
\hline \multicolumn{4}{|l|}{ INTERACTIONS } \\
\hline TMT diversity X CEO generality & & $+0.877 * *$ & \\
\hline TMT diversity X CEO power & & & $-0.649 * *$ \\
\hline ADJUSTED R-SQUARED & 0.799 & 0.801 & 0.845 \\
\hline OBSERVATIONS & 502 & 502 & 502 \\
\hline
\end{tabular}

Note. $*$ Significant at 5 percent $* *$ Significant at 1 percent.

In SEs the largest shareholder, the CEO and the chairman are very often one and the same person and CEO power is normally considerable; furthermore, one of the most difficult tasks small entrepreneurs face is how to cope with all the multifaceted skills they have to acquire that are not directly related to production. Nevertheless, compared to larger firms SEs have a smaller amount of slack resources and rarely have the option of using structural mechanisms (such as separate and parallel organizational structures, some focusing on exploration and others focusing on exploitation) to realize ambidexterity (Lubatkin et al., 2006). The findings concerning the particularly strong moderating role played by the SE CEO background and power in the relationship between TMT diversity and organizational ambidexterity are fully coherent with this shortage of structural resources and mechanisms that typically characterizes small companies.

With regard to control variables:

a) Neither TMT tenure nor TMT size showed a significant impact (the coefficients were not significant at conventional levels), while firm family ownership was found to be significantly and negatively correlated with organizational ambidexterity. We can consequently infer that family ownership, in addition to giving stability to the company structure and strategic orientation, also reduces the strategic flexibility and, consequently, a firm's capacity to operate ambidexterity, especially with regard to the ability to pursue explorative innovation;

b) Neither firm size nor firm age were found to be associated with organizational ambidexterity, and there were no significant effects of the dummy variables related to the geographical location of firms. 
Table 2 shows the results of regressing company performance on organizational ambidexterity and complexity of the industry context, as well as on the control variables (firm size, location, age, family ownership, TMT tenure and size).

Model 1 shows that SE organizational ambidexterity was found to be significantly and positively correlated with SE performance, confirming Hypothesis 4. It can be hypothesized that this particularly significant correlation is also related to small firms having a smaller amount of slack resources compared to larger companies, as well as to the fact that the determinants of the performance of medium and large firms are more complex and thereby influenced by a larger set of factors different from organizational ambidexterity (Lubatkin et al., 2006).

Table 2. Results of regressing company performance on organizational ambidexterity and complexity of the industry context

\begin{tabular}{|c|c|c|}
\hline \multicolumn{3}{|c|}{ DEPENDENT VARIABLE: ORGANIZATIONAL AMBIDEXTERITY } \\
\hline & MODEL 1 & MODEL 2 \\
\hline & \multicolumn{2}{|c|}{ LOGISTIC REGRESSION COEFFICIENTS } \\
\hline INTERCEPT & $-0.687 * *$ & $-0.754 *$ \\
\hline \multicolumn{3}{|l|}{ INDEPENDENT VARIABLES } \\
\hline Organizational Ambidexterity & $+0.908 * *$ & $+0.788 * *$ \\
\hline Complexity of the industry environment & +0.321 & +0.278 \\
\hline \multicolumn{3}{|l|}{ CONTROL VARIABLES } \\
\hline Firm size & -0.078 & -0.067 \\
\hline Firm age & -0.012 & -0.016 \\
\hline Firm family ownership & +0.121 & +0.098 \\
\hline TMT tenure & +0.031 & +0.039 \\
\hline TMT size & +0.111 & +0.054 \\
\hline NW Italy & +0.065 & +0.076 \\
\hline NE Italy & +0.008 & -0.006 \\
\hline South Italy & -0.032 & +0.048 \\
\hline \multicolumn{3}{|l|}{ INTERACTIONS } \\
\hline Organizational ambidexterity X Complexity of the industry & & $+1.135^{* *}$ \\
\hline ADJUSTED R-SQUARED & 0.845 & 0.811 \\
\hline OBSERVATIONS & 502 & 502 \\
\hline
\end{tabular}

Note. $*$ Significant at 5 percent $* *$ Significant at 1 percent.

Model 2 shows that the interaction between organizational ambidexterity and complexity of the industry context was found to be positively and significantly correlated with SE performance, confirming Hypothesis 5. Top management discretion when taking strategic decisions (Finkelstein \& Hambrick, 1990) highly depends on the complexity of the contexts in which a firm operates. In high-complexity contexts SE TMT can choose from a large number of options, and this increases the level at which organizational outcomes reflect organizational flexibility and ambidexterity. On the contrary, in low-complexity environments, the limited number of possible strategic options reduces the level at which organizational outcomes reflect organizational capacity to concurrently pursue exploratory and exploitative innovation. In this study, complexity of the industry environment is valued 1 if the firm operates in the fashion industry and 0 if the firm operates in other low-technology manufacturing industries. Consequently, our findings also demonstrate that fashion companies can be seen as paradigmatic examples of firms which need to be ambidextrous.

None of the control variables had a significant impact on company performance: all the coefficients were not significant at conventional levels.

\subsection{Robustness Checks}

In order to test the robustness of the results and following the literature of multiple hypotheses testing (e.g., 
Romano, Shaikh, \& Wolf, 2010) the Benjamini-Hochberg False Discovery Rate, the Bonferroni correction, and the Bonferroni-Holm correction were applied.

When using the Benjamini-Hochberg False Discovery Rate of correction, the p-values of all the significant coefficients (for all the Models) continued to be so at conventional levels. Even when using the other two more stringent methods of correction, all estimates continued to be statistically significant at conventional levels with the exception of the family ownership-organizational ambidexterity coefficient (that was found to be not significant for both the Bonferroni and the Bonferroni-Holm corrections). It can therefore be concluded that the findings of this study are on the whole robust to multiple hypothesis testing correction.

Finally, the robustness of the results was tested on a different sample. The second initial sample consisted of 1,840 independent SEs operating in Italy in low-technology manufacturing industries. This sample was also selected by way of a two-step process. Firstly, by stratified random sampling based on size and business sector, a sample of 920 firms primarily operating in one of the sectors of the fashion industry was selected, which in 2016 were independent (i.e. not part of a group), had a regular balance sheet and a turnover below 5 million Euros. Secondly, a sample of the same size (920 firms) was selected comprising firms endowed with the same characteristics but primarily operating in the other (i.e. non-fashion) low-technology manufacturing industries. This second sample was also selected by stratified random sampling based on size and business sector. Company performance variable was calculated on balance sheet data related to the 2016 financial year and extracted from the CERVED Database (Note 1). The variables regarding firm size, location, age and industry were also extracted from the CERVED Database. The dataset of all the other variables was built by sending a questionnaire to the CEO of each of the 1,840 small firms included in the sample. $22.1 \%$ of firms sent back complete responses (200 fashion companies and 207 non-fashion companies). The results obtained by applying moderate regression analyses to this dataset confirmed all the findings: i) a significant and positive relationship was found between SE TMT diversity and organizational ambidexterity; ii) the interaction between TMT diversity and CEO generality was found to be positively and significantly correlated with SE ambidexterity; iii) the interaction between TMT diversity and CEO power was found to be negatively and significantly correlated with SE ambidexterity; iv) a significant and positive relationship was found between SE organizational ambidexterity and performance; $v$ ) this relationship was found to be positively moderated by the level of complexity of the industry environment; vi) the coefficients of all the mentioned variables proved to be significant at $1 \%$ or $5 \%$; vii) apart from firm family ownership (which was found significantly and negatively correlated with organizational ambidexterity) none of the control variables were found to have a significant impact; vii) the results proved to be robust to multiple hypothesis testing corrections (the Benjamini-Hochberg False Discovery Rate, the Bonferroni correction, and the Bonferroni-Holm correction).

\section{Conclusions}

Although SEs represent a fundamental component of every nation's economy, the emerging dialogue on the relationships between top management characteristics, the CEO's role, ambidexterity and performance has mainly focused on large firms and never specifically on SEs.

This study contributed to this emerging dialogue as follows. First, it demonstrated that SE TMT diversity is particularly beneficial for strategic thinking and for facilitating simultaneously pursuing exploratory and exploitative innovation. Compared to larger firms, in the case of SEs the number of hierarchical levels is far lower and TMTs are closer to the firm's competencies, the markets and their clients. SE TMTs are consequently better positioned to evaluate when and how to exploit existing competencies as well as to explore new market opportunities.

Second, this study demonstrated that SE CEO generality (CEO Power) strongly and positively (negatively) moderates the relationship between TMT diversity and organizational ambidexterity. This particularly strong moderating role played by SE CEO background and power is probably mainly the result of the fact that, compared to larger firms, SEs cannot afford to duplicate their organizational structures and mechanism to contemporarily pursue exploration and exploitation.

Third, in addition to demonstrating that organizational ambidexterity is a key driver for value creation also in the case of SEs, the results of this study shed light on the moderating role played by the complexity of the industry environment in the relationships between SE ambidexterity and company performance. In this connection, this study found that fashion companies can be considered as paradigmatic examples of firms which need to be ambidextrous. They produce and sell creative products in order to satisfy continuously changing needs and are permanently oriented to explore new designs, products, channels of distribution, and markets. At the same time, they must also have the ability to transform ideas into products, products into sales, and sales into profits. This 
means that they must also be able to exploit existing designs, customers, products, distribution channels and markets (Li, 2013).

This research, however, has some limitations. First, it analyses firms in only one geographical context (Italy) whose specific characteristics, in terms of economic and industrial structure, certainly limit the generalizability of the findings.

Second, the analysed sample consisted exclusively of firms operating in low-technology manufacturing industries and this aspect limits the generalizability of the results to either high technology manufacturing firms and service firms.

Third, this study is based on single respondents from each firm in the sample. Using multiple respondents would have allowed more reliable measures.

\section{References}

Adams, R. B., Almeida, H., \& Ferreira, D. (2005). Powerful CEOs And Their Impact on Corporate Performance. Review of Financial Studies, 18(4), 1403-1432. http://dx.doi.org/10.1093/rfs/hhi030

Andriopoulos, C., \& Lewis, M. W. (2009) Exploitation-Exploration Tensions and Organizational Ambidexterity: Managing Paradoxes of Innovation. Organization Science, 20(4), 696-717. http://dx.doi.org/10.1287/orsc.1080.0406

Atuahene-Gima, K. (1996). Market Orientation and Innovation. Journal of Business Research, 35(2), 93-103, https://doi.org/10.1016/0148-2963(95)00051-8

Blau, P. (1977). Inequality and Heterogeneity. New York, NY: Free Press.

Bunderson, J. S., \& Sutcliffe, K. M. (2002). Comparing Alternative Conceptualizations of Functional Diversity in Management Teams: Process and Performance Effects. Academy of Management Journal, 45(5), 875-893. http://dx.doi.org/10.2307/3069319

Burke, I. G., \& Jarrat, D. (2004). The Influence of Information and Advice on Competitive Strategy Definition in Small and Medium Sized Enterprises. Qualitative Market Research, 7(2), 126-138. http://dx.doi.org/10.1108/13522750410530039

Carmeli, A. \& Schaubroeck, J. (2006). Top Management Team Behavioral Integration, Decision Quality, and Organizational Decline. Leadership Quarterly, 17(5), 441-453. http://dx.doi.org/10.1016/j.leaqua.2006.06.001

Certo, S. T., Lester, R. H., Dalton, C. M., \& Dalton, D. R. (2006). Top Management Teams, Strategy and Financial Performance: A Meta-Analytic Examination. Journal of Management Studies, 43(4), 813-839. http://dx.doi.org/ 10.1111/j.1467-6486.2006.00612.x

Chattopadhyay, P., Glick, W. H., Miller, C. C., \& Huber, G. P. (1999). Determinants of Executive Beliefs: Comparing Functional Conditioning and Social Influence. Strategic Management Journal, 20(8), 763-789. http://dx.doi.org/10.1002/(SICI)1097-0266(199908)20:8<763::AID-SMJ46>3.0.CO;2-D

Ciampi, F. (2015). Corporate Governance Characteristics and Default Prediction Modeling for Small Enterprises. An Empirical Analysis of Italian Firms. Journal of Business Research, 68 (5), 1012-1025. http://dx.doi.org/10.1016/j.jbusres.2014.10.003

Ciampi, F., \& Gordini, N. (2013). Small Enterprise Default Prediction Modeling through Artificial Neural Networks: An Empirical Analysis of Italian Small Enterprises. Journal of Small Business Management, 51(1), 23-45. http://dx.doi.org/10.1111/j.1540-627X.2012.00376.x

Cohen, J., Cohen, P., West, S. G., \& Aiken, L. S. (2003). Applied Multiple Regression/Correlation Analysis for the Behavioral Sciences. Hillsdale, NJ: Lawrence Erlbaum Associates.

Custodio, C., Ferreira, M. A., \& Matos, P. (2013). Generalists versus Specialists: Lifetime Work Experience and CEO Pay. Journal of Financial Economics, 108(2), 471-492. http://dx.doi.org/ 10.1016/j.jfineco.2013.01.001

Dahlin, K. B., Weingart, L. R., \& Hinds, P. J. (2005). Team Diversity and Information Use. Academy of Management Journal, 48(6). http://www.jstor.org/stable/20159732

Daily, C. M., \& Johnson, J. L. (1997). Sources of CEO Power and Firm Financial Performance: A Longitudinal Assessment. Journal of Management, 23(2), 97-117. http://dx.doi.org/10.1177/014920639702300201

Finkelstein, S., \& Hambrick, D. C. (1990). Top-Management-Team Tenure and Organizational Outcomes: The 
Moderating Role of Managerial Discretion. Administrative Science Quarterly, 35(3), 484-503. http://www.jstor.org/stable/2393314

Floyd, S. W., \& Lane, P. J. (2000). Strategizing Throughout the Organization: Managing Role Conflict in Strategic Renewal. Academy of Management Review, 25(1), 154-177. http://www.jstor.org/stable/259268

Ghemawat, P., Costa, R., (1993). The Organizational Tension between Static and Dynamic Efficiency. Strategic Management Journal, 14(1), 59-73. http://dx.doi.org/10.1002/smj.4250141007

Gibson, C. B, \& Birkinshaw, J. (2004) The Antecedents, Consequences, and Mediating Role of Organizational Ambidexterity. Academy of Management Journal, 47(2), 209-226. https://doi.org/10.2307/20159573

Hambrick, D. C. (1994). Top Management Groups: A Conceptual Integration and Reconsideration of the "Team" Label. Research in Organizational Behavior, 16(3), 171-213.

Hambrick, D. C. (1995). Fragmentation and the Other Problems CEOs Have with Their Top Management Teams. California Management Review, 37(3), 110-127. http://dx.doi.org/10.2307/41165801

Hambrick, D. C., \& Mason, P. A. (1984). Upper Echelons: The Organization as a Reflection of Its Top Managers. Academy of Management Review, 9(2), 193-206. http://www.jstor.org/stable/258434

Hambrick, D. C., Cho, T. S., \& Chen, M. J. (1996) The Influence of Top Management Team Heterogeneity on Firms' Competitive Moves. Administrative Science Quarterly, 41(4), 659-684. http://www.jstor.org/stable/2393871

Hambrick, D.C., Finkelstein, S., \& Mooney, A. C. (2005). Executive Job Demands: New Insights for Explaining Strategic Decisions and Leader Behaviors. Academy of Management Review, 30(3), 472-491. http://www.jstor.org/stable/20159139

Jansen, J. J. P., George, G., Van den Bosch, F. A. J., \& Volberda, H. W. (2008). Senior Team Attributes and Organizational Ambidexterity: The Moderating Role of Transformational Leadership. Journal of Management Studies, 45(5), 982-1007. http://dx.doi.org/10.1111/j.1467-6486.2008.00775.x

Li, C.-R. (2013). How Top Management Team Diversity Fosters Organizational Ambidexterity. Journal of Organizational Change Management, 26(5), 874-896. http://dx.doi.org/10.1108/JOCM-06-2012-0075

Ling, Y, \& Kellermans, F. (2010). The Effects of Family Firm Specific Sources of TMT Diversity: The Moderating Role of Information Exchange Frequency. Journal of Management Studies 47(2), 322-344. http://dx.doi.org/10.1111/j.1467-6486.2009.00893.x

Lubatkin, M. H., Simsek, Z., Ling, Y., \& Veiga, J. F. (2006). Ambidexterity and Performance in Small-to Medium-Sized Firms: The Pivotal Role of Top Management Team Behavioral Integration. Journal of Management, 32(5), 646-672. https://doi.org/10.1177/0149206306290712

Milliken, F. J., \& Martins, L.L. (1996). Searching for Common Threads: Understanding the Multiple Effects of Diversity in Organizational Groups. Academy of Management Review, 21(2), 402-433. http://dx.doi.org/10.5465/AMR.1996.9605060217

Parida, V., Lahti, T, \& Wincent, J (2016). Exploration and Exploitation and Firm Performance Variability: A Study of Ambidexterity in Entrepreneurial Firms. International Entrepreneurship and Management Journal, 12(4), 1147-1164. http://dx.doi.org/10.1007/s11365-016-0387-6

Romano, J., Shaikh, A., S., \& Wolf, M. (2010). Hypothesis Testing in Econometrics. Annual Review of Economics, 2(1), 75-105. http://dx.doi.org/10.1146/annurev.economics.102308.124342

Song, L., \& Jin, L. (2017). Strategic Orientation and Performance of New Ventures: Empirical Studies Based on Entrepreneurial Activities in China. International Entrepreneurship and Management Journal, 13(4), 989-1012. http://dx.doi.org/10.1007/s11365-017-0433-z

Zhou, X. (2001). Understanding the Determinants of Managerial Ownership and the Link Between Ownership and Performance: Comment. Journal of Financial Economics, 62, 559-571. http://dx.doi.org/10.1016/S0304-405X(01)00085-X

\section{Note}

Note 1. The CERVED Database includes complete financial records of over 1.000,000 Italian companies. 


\section{Copyrights}

Copyright for this article is retained by the author(s), with first publication rights granted to the journal.

This is an open-access article distributed under the terms and conditions of the Creative Commons Attribution license (http://creativecommons.org/licenses/by/4.0/). 